\title{
Strain-rate dependency of bio-based cellular materials un- der a large range of temperature
}

\author{
Louise Le Barbenchon ${ }^{1, *}$, Philippe Viot ${ }^{1}$, Jérémie Girardot ${ }^{1}$, and Jean-Benoît Kopp ${ }^{1,}$ \\ ${ }^{1}$ Arts et Metiers Institute of Technology, Univ. of Bordeaux, CNRS, Bordeaux INP, INRAE, HESAM \\ Université, I2M Bordeaux, F-33400 Talence, France
}

\begin{abstract}
.
Polymeric cellular materials are used in many different application domains such as transport, sport, food, health and energy. Therefore, the conditions of use of these materials represent wide temperature and strain-rate ranges. The mechanical behaviour of these foams demonstrate a strong dependency to it. In order to be able to predict such dependency, its origin has to be better understood. For this study, a bio-based cellular material, agglomerated cork, has been chosen to evaluate the temperature and strain-rate dependency of the mechanical behaviour. The visco-elastic behaviour of the material was first studied between $-80^{\circ} \mathrm{C}$ and $100^{\circ} \mathrm{C}$ at frequencies between $0.01 \mathrm{~Hz}$ and $100 \mathrm{~Hz}$. The compressive mechanical behaviour was then studied on a large range of temperature (from $-30^{\circ} \mathrm{C}$ to $100^{\circ} \mathrm{C}$ ) and strain rates (from $4.210^{-5} \mathrm{~s}^{-1}$ to $1250 \mathrm{~s}^{-1}$ ). A specific set-up was finally used to operate dynamic tests at low and high temperature. These results were used to discuss the evolution of the mechanical beahviour with these environnemental conditions based on the knowledge of the mechanical behaviour of the constitutive materials.
\end{abstract}

\section{Introduction}

The demand for lighter and bio-sourced materials is currently increasing because of emerging concerns about global warming. Cork presents a large set of properties (fire resistant, impact absorbing, phonic isolation ...) due to its foam structure and polymeric composition [1]. It is then an excellent candidate for a wide range of application domains. One of them is aeronautical parts with an usual temperature range around $\left[-30^{\circ} \mathrm{C}, 80^{\circ} \mathrm{C}\right]$ and loading conditions that can vary from an impact due to a tool drop to the protection of the structure from fragment impact in the space.

An increase in macroscopic stresses was usually noted with the increase in the initial strain-rate as have shown several impact tests achieved with a drop tower [2-5].

This kind of loading coupled with temperature variation shows no important changes in the mechanical behaviour between $21^{\circ} \mathrm{C}$ and $50^{\circ} \mathrm{C}$ [6]. However, another study reports that between $-30^{\circ} \mathrm{C}$ and $100^{\circ} \mathrm{C}$, an important decrease in the absorbed energy during an impact is observed when the temperature increases [7].

Such results demonstrate the necessity of studying the mechanical behaviour of materials under temperature and strain rate working conditions. However, as they are performed at the

\footnotetext{
*e-mail: louise.le \_barbenchon@ensam.eu
} 
industrial part scale, they do not allow to understand the underlying micromechanisms (at the scale of the cell or the bead) that cause such dependencies in the mechanical behaviour.

Even if it was not discussed by the authors, the reason of such observations seems to be linked to the glass-transition temperature $T_{g}$. This temperature is around $20^{\circ}$ for cork agglomerates [8] and marks the transition between the glassy stage and the rubbery one.

How temperature and strain-rate affect independently and together the mechanical behaviour of cellular polymeric materials is one of the key to better predict and simulate the mechanical behaviour of industrial parts.

Compression tests were conducted on a cork agglomerate at several temperatures and at different frequency (small strains) or strain-rates (large strains). To reproduce working conditions, a thermal chamber was specially designed to perform compression tests in dynamic regime at high and low temperatures with a constant strain rate.

\section{Material \& Methods}

\subsection{Material}

Agglomerated cork is obtained by mixing small beads $(\varnothing \approx[0.5,1] \mathrm{mm})$ together with a bio-sourced thermosetting resin (polyfurfuryl alcohol). The mixture is then compressed into a mold to obtain a $1000 \times 500 \times 150 \mathrm{~mm}^{3}$ block. During the molding, the compression induces a preferential orientation of the beads in the (Oxy) plane [9].

In this study, one of the two directions induced by the bead flattening is considered (fig. 1(a)): the $(\mathrm{Oz})$ direction that will be called out-of-plane direction (OP). The polymerization was made in an autoclave at $130^{\circ} \mathrm{C}$ during 12 hours. Large plates were then machined from the block.
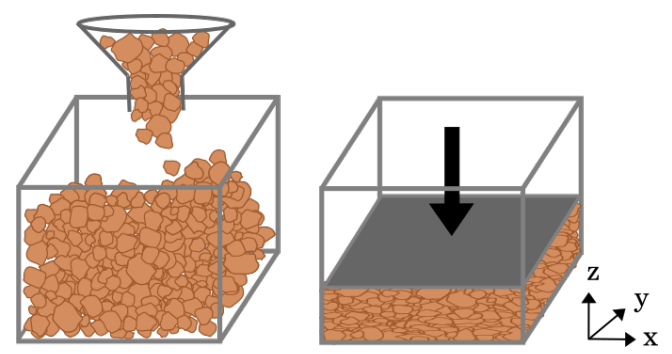

(a) Compression step dring the manufacturing process.

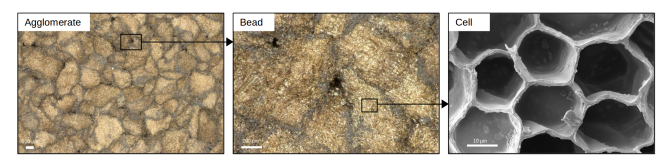

(b) Resulting multi-scale structure.

Figure 1. Manufacturing process. Cork beads coated with resin are poured inside a metallic mold then compressed uni-axially in the $(\mathrm{Oz})$ direction.

\subsection{Vibratory tests}

The viscoelastic behaviour was determined by means of Dynamic Mechanical Analysis (DMA) in compression mode with a Mettler Toleda I controlled by STARe software. The 
sample underwent repeated small-amplitude strains in a cyclic manner. Molecules perturbed in this way store a portion of the imparted energy elastically and dissipate a portion in the form of heat [10]. In this case, the modulus acquires a complex form, $E^{*}=E^{\prime}+i E^{\prime}$. The quantity E', the storage modulus, is a measure of the energy stored elastically, whereas E", the loss modulus, is a measure of the energy lost as heat or molecular rearrangements during the deformation [11].

Temperature scans were performed from $-80^{\circ} \mathrm{C}$ to $100^{\circ} \mathrm{C}$ with $10^{\circ} \mathrm{C}$ steps maintained for $30 \mathrm{~min}$ before a measurement between a $0.01 \mathrm{~Hz}$ frequency to a $100 \mathrm{~Hz}$ frequency at an imposed displacement of $5 \mu \mathrm{m}$. Samples were cubic with a $5 \mathrm{~mm}$ side length, the corresponding nominal strain was $0.1 \%$ and a pre-strain of $0.01 \%$ was chosen.

\subsection{Quasi-static tests}

\subsubsection{Tests at room temperature}

$20 \times 20 \times 20 \mathrm{~mm}^{3}$ samples were cut. Their density was measured and stands around 0.42 . Samples were conditioned at a $50 \%$ relative humidity to reduce the potential effect of hygrometry [12].

An electromechanical traction/compression machine (Zwick Roell 250) with a load cell capacity of $250 \mathrm{kN}$ was used. The imposed speed of the lower punch was set at $0.05,5$ and $500 \mathrm{~mm} \mathrm{~min}^{-1}$ corresponding to average strain rates of $4.2 \times 10^{-5} \mathrm{~s}^{-1}, 4.2 \times 10^{-3} \mathrm{~s}^{-1}$ and $4.2 \times 10^{-1} \mathrm{~s}^{-1}$.

\subsubsection{Compression at different temperatures}

At $4.2 \times 10^{-3} s^{-1}$, four temperature conditions were set: $-30^{\circ} \mathrm{C},-10^{\circ} \mathrm{C}, 80^{\circ} \mathrm{C}$ and the ambient temperature measured at $24^{\circ} \mathrm{C}$. The temperature was controled in a chamber (Zwick) equipped with a heater (for the $80^{\circ} \mathrm{C}$ temperature) and a nitrogen cooling connector (for the temperatures of $-30^{\circ} \mathrm{C}$ and $-10^{\circ} \mathrm{C}$ ) with an induced circulation to keep the temperature constant in the chamber during the tests. Samples were placed at least one hour beforehand in the chamber at the wanted temperature in order to reach a stabilised temperature. The temperature was checked using an infrared temperature sensor.

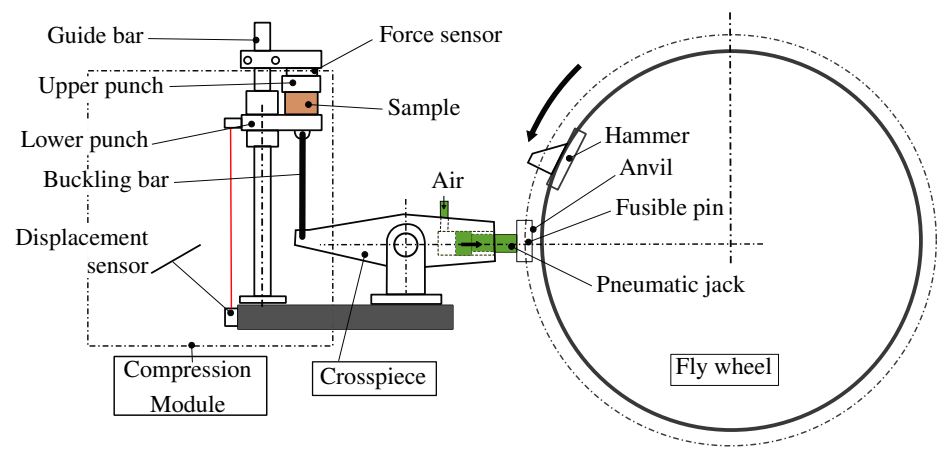

Figure 2. Scheme of the flywheel and compression device [13]. 


\subsubsection{Experimental compression curves post-treatment}

From the force $F(t)$ and the displacement $d(t)$ data, macroscopic stress/strain curves were deducted by calculating nominal stress $\left(\sigma=\frac{F(t)}{S_{0}}\right)$ and true strain $\left(\varepsilon=\ln \left(\frac{l_{0}-d(t)}{l_{0}}\right)\right), l_{0}$ being the initial height of the sample.

\subsection{Dynamic tests}

\subsubsection{Fly wheel}

To reach higher levels of strain rates, cork samples were tested on a flywheel. It is an original apparatus which allows to dynamically load specimens at intermediate strain rates (from 50 to $800 s^{-1}$ ) [14].

A test on the flywheel can be described as follows (see Fig. 2): the heavy metallic wheel ( $1 \mathrm{~m}$ diameter, $617 \mathrm{~kg}$ ) is set in motion and its rotation velocity is accurately controlled by an asynchronous motor. A hammer fixed on the wheel is the impactor of this machine and can impose either tensile loadings on metallic and composite materials or compressive loading on cellular materials according the complementary apparatus being used [15].

To carry out compression tests on cork material, when the desired rotation speed of the wheel is reached, a pneumatic jack pushes the anvil alongside the wheel. The anvil is then grabbed by the hammer inducing a rapid rotation of the crosspiece. This rotation imposes the displacement of the buckling bar and the lower punch. Once the compressive force reaches a predetermined threshold value, the bar buckles and interrupts further specimen compression. The unloading however is not controlled and is not operated at the same strain rate.

This device, due to its high moment of inertia $\left(77 \mathrm{~kg} \mathrm{~m}^{-2}\right)$, enables the compression of specimens under constant velocity, since the specimen does not absorb enough energy to slow the wheel down.

The compressive stress is measured by a piezo-electric KISTLER 9031A force sensor located behind the upper punch and coupled with a charge amplifier KISLTER 5018A1000. The lower punch displacement is determined by a dynamic laser sensor Micro-epsilon LD162727. Raw signals (displacement and force) were directly used as they presented low noises and are post-treated just like quasi-static tests.

\subsubsection{Split Hopkinson Bars}

The cork samples were dynamically tested on Split Hopkinson Pressure Bars. The SHPB (Split Hopkinson Pressure Bar) system, also called Kolsky's apparatus, is a commonly used experimental technique in the study of constitutive laws of materials at high strain rates.

A typical SHPB test system with aluminum bars with a $25 \mathrm{~mm}$ diameter was used. It is composed of a long input $(3 \mathrm{~m})$ and output bars $(2 \mathrm{~m})$ with a short specimen placed between them. With the impact of a projectile at the free end of the input bar, a compressive longitudinal incident wave $\varepsilon_{i}(t)$ is created in the input bar. Once the incident wave reaches the interface specimen-bar, a reflected pulse $\varepsilon_{r}(t)$ in the input bar and a transmitted pulse $\varepsilon_{t}(t)$ in the output bar are developed. With gages glued on the input and output bars, these three basic waves are recorded. Their processing allows for the knowledge of forces and particle velocities at both faces of the specimen.

What is needed is the value of forces and particle velocities at specimen faces. They are calculated with waves shifted at the same points. For slender elastic bars, it is assumed that elastic waves propagate without dispersion and they are simply time shifted to bar ends.

Using the superposition principle, the velocities and forces at both specimen faces are given by the equations 1 and 2 . 


$$
\begin{gathered}
V_{i}(t)=-c\left(\varepsilon_{i}(t)-\varepsilon_{r}(t)\right) \\
\mathrm{V}_{o}(t)=-c \varepsilon_{t}(t) \\
F_{i}(t)=S_{b} E\left(\varepsilon_{i}(t)+\varepsilon_{r}(t)\right) \\
\mathrm{F}_{o}(t)=S_{b} E \varepsilon_{t}(t)
\end{gathered}
$$

where $V$ is the velocity, $F$ is the force, $S_{b}$ is the area of the bars, $E$ is the Young's modulus of the bars and $c$ is the wave speed in bars. Subscripts $i$ and $o$ indicate the input and output side, respectively. Assuming that the stresses and the strains are homogeneous in the specimen, the average strain, the average strain rate and the average stress in the specimen, as a function of time, are given by the expressions (3), where $l_{S}$ and $S_{S}$, respectively, stand for the specimen length and cross-sectional area, and $U$ is the displacement of the interface considered.

$$
\begin{gathered}
\bar{\varepsilon}=\frac{U_{i}(t)-U_{o}(t)}{l_{S}} \\
\overline{\dot{\varepsilon}}=\frac{V_{i}(t)-V_{o}(t)}{l_{S}} \\
\bar{\sigma}=\frac{F_{i}(t)-F_{o}(t)}{2 S_{S}}
\end{gathered}
$$

These equations correspond to the standard analysis of the test and were used for the post-treatment of the signal obtained for the strain gauges placed on the input and output bars. Cylindrical samples with a diameter of $24 \mathrm{~mm}$ and a thickness of $5 \mathrm{~mm}$ were tested.

\section{Results \& Discussions}

\subsection{Visco-elastic behaviour}

The storage modulus E' evolution with temperature and frequency from compressive DMA results is shown in Fig. 3.

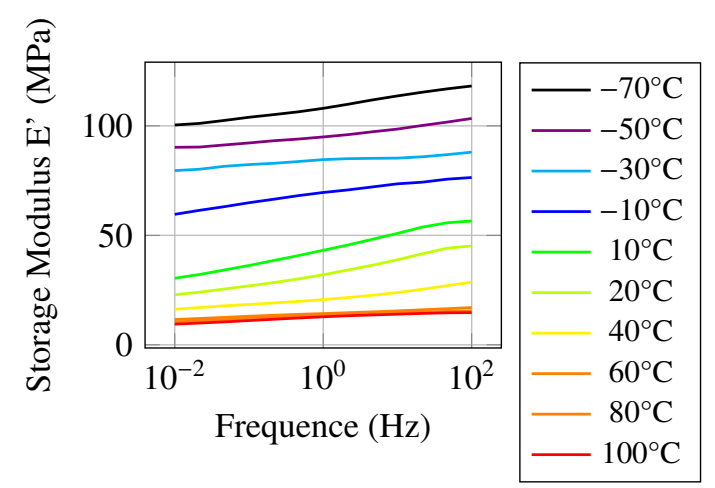

Figure 3. Compressive DMA spectra of cork agglomerate tested in the out-of-plane direction at several temperatures.

The storage modulus E' decreases largely with increasing temperature due to the softening of the cell wall material, as already noted for raw cork and other cork agglomerates $[10,12,16]$. A similar tendency concerning the storage modulus was found for other cork agglomerates with PFA resin [16]. It tends also to increase with the test frequency. 
From $-80^{\circ} \mathrm{C}$ to ambiant temperature $\left(\mathrm{ca} 20^{\circ} \mathrm{C}\right)$, the decrease in $\mathrm{E}^{\prime}$ is more and more important (fig. 3). This is related to the occurrence of a relaxational process. This dynamic transition can be assigned to a $\alpha$-relaxation of one of the main cork cell wall components, suberin [12]. Then from $20^{\circ} \mathrm{C}$ to high temperatures, the decrease of the storage modulus is less and less important. Between 60 and $100^{\circ} \mathrm{C}$, it is even negligible. For this kind of cork agglomerates, $20^{\circ} \mathrm{C}$ is considered to be the glass transition temperature $T_{g}$ [8], which is the temperature at which the modification of the mechanical behaviour in the $\alpha$-transiton in maximal. Given the results from fig. 3, it seems that the rubbery plateau is reached above $60^{\circ} \mathrm{C}$ for a large range of frequency. However, at low temperatures the glassy plateau is not reached.

In the light of these results, the non-linear mechanical behaviour of cork agglomerates was then studied.

\subsection{Temperature effect}

Fig.4 shows experimental stress/strain curves for quasi-static compression tests at several temperatures from $-30^{\circ} \mathrm{C}$ to around $100^{\circ} \mathrm{C}$ for cork agglomerates tested in the out-of-plane (OP) direction at $5 \mathrm{~mm} / \mathrm{min}$. For each temperature, cork agglomerates show a mechanical behaviour typical of cellular material with the three stages: linear, plateau and densification.

As already observed in the case of many polymeric materials a higher stress is required to achieve the same macroscopic strain as temperature is decreasing $[17,18]$.

The temperature dependency of the mechanical behaviour of cork agglomerates is not surprising. Indeed, the whole material is a composite made of several polymeric materials. On one hand, the stiffness of the thermosetting resin is expected to have a relatively linear dependency to the temperature on a wide range of temperature (the glass transition temperature $T_{g}$ being high). On the other hand, cork cells walls are made of several thermoplastic polymeric substances whose behaviour is highly temperature dependant $[19,20]$. It seems natural that the mechanical behavior of agglomerated cork is also strongly dependant of the temperature.

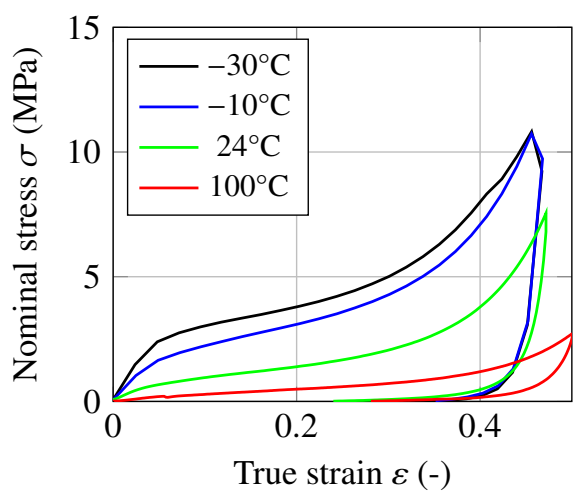

Figure 4. Experimental stress/strain curves of cork agglomerates samples loaded in compression at a mean strain rate of $4.210^{-3} \mathrm{~s}^{-1}$ in the out-of-plane (OP) direction at several temperatures.

The macroscopic strain $\varepsilon_{f r a c}^{*}(T)$ at which fracture is observed at the sample surface is decreasing with the temperature. For $-30^{\circ} \mathrm{C}$ and $-10^{\circ} \mathrm{C}$, fracture is respectively observed at a strain of 0.42 and 0.45 while no fracture is noticed for higher temperatures. Therefore lower 


\section{DYMAT 2021}

temperature leads to earlier macroscopic failure as $\varepsilon_{\text {frac }}^{*}(T)$ decreases with temperature. In agglomerated cork, fracture mechanisms are mostly intra-granular [8]. This decrease in the fracture strain with temperature would thus be mainly due to the tensile embrittlement of the cork beads, and more precisely of the cork cell walls, with the drop in temperature.

\subsection{Strain rate effect}

Fig. 5 shows the stress/strain curves obtained from compression tests on agglomerated cork specimens at room temperature $\left(24^{\circ} \mathrm{C}\right)$ carried out at different strain rates. No crack was observed at the sample surface for any strain-rate. For quasi-static strain-rates, temperature seems then to have a greater effect on the fracture mechanisms.

The bigger the strain rate, the bigger stresses reached during the compression as already reported [21].

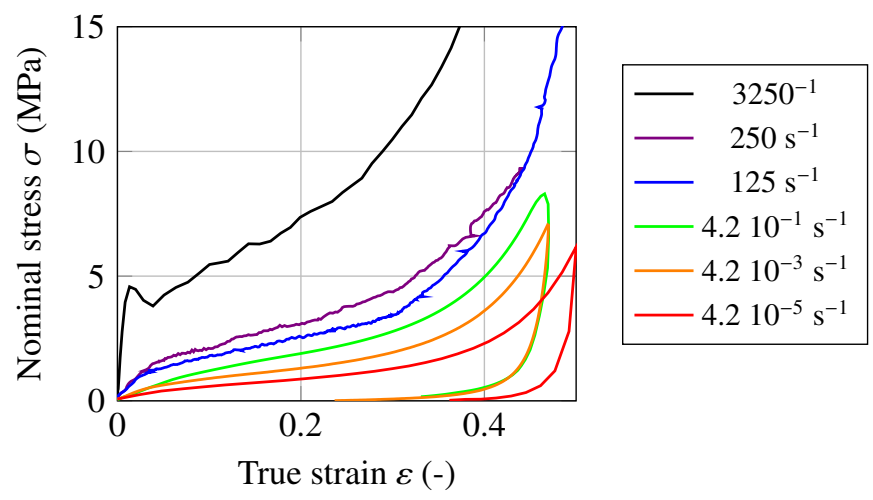

Figure 5. Experimental stress/strain curves of cork agglomerates samples loaded in compression at several strain rates in the out-of-plane $(\mathrm{OP})$ direction at ammbiant temperature $\left(24^{\circ} \mathrm{C}\right)$.

In quasi-static regime (at $4.210^{-5} ; 4.210^{-3}$ and $4.210^{-1}$ ), the strain rate varies each time by two decades and a clear difference is observed between each curve (fig. 5).

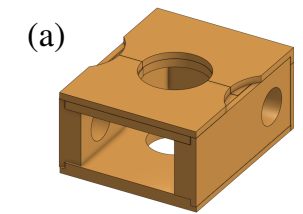

(b)

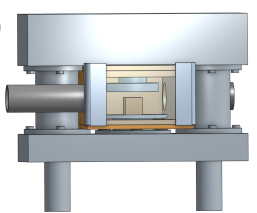

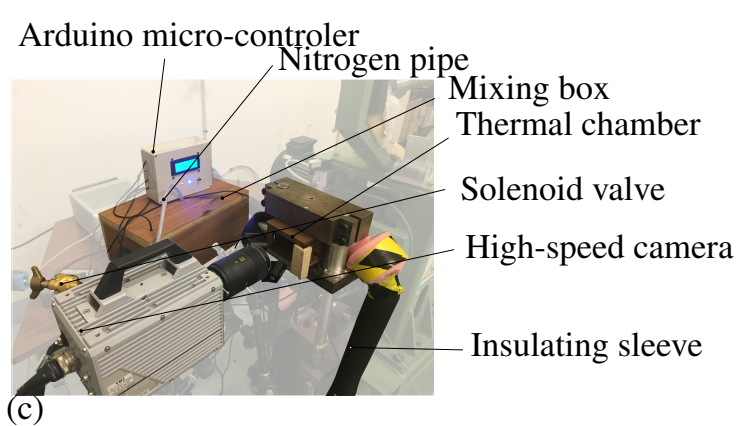

(c)

Figure 6. (a) Thermal set-up with the CAD of the thermal chamber. (b) CAD of thermal chamber placed in the laoding area. (c) Experimental set-up of compression tests at intermediate strain rate at controled temperature. 
In dynamic regime (at $125,250 \mathrm{~s}^{-1}$ and $3250 \mathrm{~s}^{-1}$ ), such a similar amplitude in strain rates (of 3 decades) was not possible. While compression tests at 125 and $250 \mathrm{~s}^{-1}$ show a similar mechanical response, compression tests realised on SHPB show a reduced plateau phase.

There are several hypotheses to explain such behaviour. First, the mechanical behaviour of the constitutive materials is very dependant of the strain rate. It seems to be the main factor for the increase in the stress between $4.210^{-5}$ and $250 \mathrm{~s}^{-1}$. A supplementary effect causing the stresses to increase so quickly that the plateau phase is very reduced could be due to the gas enclosed in cork cells. It has already been shown to be a crucial factor for polymeric foam when dynamically loaded [15, 22].

Another hypothesis would that even if no crack is observed at the sample surface during the SHPB test, fracture mechanisms have already occured. Therefore, it would not be the mechanical response of the cellular material that is hereby showed but the behaviour of a granular media. Intermediar strain rates as well as more local observations should be undetaken to validate such results.

\subsection{Coupled effect of temperature and strain-rate}

Loadings coupling both parameters (strain rate and temperature) are needed to better capture the effect of strain-rates and temperature on the mechanical behaviour of suc materials. However, the assumption of a constant temperature during intermediate speed compression tests is difficult to make. In order to perform tests at dynamic regime in temperature, a thermal chamber for the fly wheel apparatus was thus designed and build (fig.6a). The reduced available space around the loading area principally dictated design choices along with the requirement to be able to observe sample deformation (fig.6b).

The inner of the thermal chamber can be conditionned at a desired temperature $T_{i}$ thanks to an air circuit whose temperature is controled using an Arduino micro-controler (fig. $6 \mathrm{c}$ and fig.6d). The two temperature sensors, placed on either side of the thermal chamber, measure respectively $T_{a}$ and $T_{b}$. The temperature of the thermal chamber $T_{\text {chamber }}$ is then calculated from these measurements,

$$
T_{\text {chamber }}=\frac{T_{a}+T_{b}}{2} .
$$

If $T_{\text {chamber }}<T_{i}$, the resistor inside the mixing box is activated. The air inside is heated and injected into the thermal chamber through insulating sleeves thanks to fans until $T_{\text {chamber }}$ is reached. If $T_{\text {chamber }}>T_{i}$, nitrogen is injected inside the mixing box in order to cool down the temperature of the air flow.

Compression tests were operated at $-20^{\circ} \mathrm{C}$ and $73^{\circ} \mathrm{C}$ and 63 and $187 s^{-1}$. The resulting experimental curves can be found in fig. 7.

Dynamic tests at $73^{\circ} \mathrm{C}$ above the glass transition temperature induce stresses that are similar to those obtained with quasi-static tests at ambiant temperature (fig. 4 and fig.5). At $73^{\circ} \mathrm{C}$, a small variation in strain rate (from 63 to $187 \mathrm{~s}^{-1}$ ) does not change the mechanical response for small strains. Therefore, even in the dynamic regime, at $\mathrm{T}=73^{\circ} \mathrm{C}$ cork agglomerate are still is their rubbery state. However, the mechanical behaviour differ above a 0.1 strain. That could come from a higher compression of the enclosed gas at higher strain-rates.

On the contrary, at $-20^{\circ} \mathrm{C}$, the same variation in strain-rate gives two very different mechanical behaviour. At the greatest strain rate, preamature fracture appears at $\varepsilon=0.24$ while the first crack is observed at $\varepsilon=0.4$ for $63 s^{-1}$. Dynamic loading conditions alone were not sufficient to cause fracture mechanisms to happen. But when combined with low temperature, cork agglomerates seems to become really fragile. 


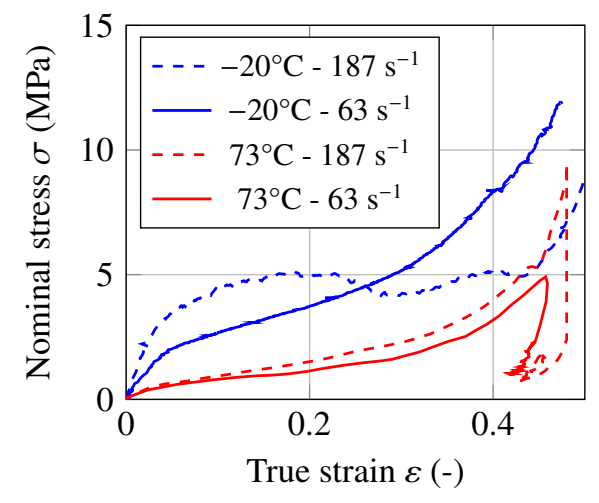

Figure 7. Experimental stress/strain curves of cork agglomerates samples loaded in compression in dynamic regime at different temperatures in the out-of-plane $(\mathrm{OP})$ direction.

Before fracture, a large decrease in stresses is observed between $187 \mathrm{~s}^{-1}$ and $63 \mathrm{~s}^{-1}$. It could be linked to the fact that the constitutive materials are not in the glassy plateau but in the $\alpha$-transition. Therefore, their mechanical behaviour would strongly vary with strain-rate at a given temperature.

\section{Conclusions \& Perspectives}

A large range of strain-rates and temperatures were imposed to cork agglomerate samples. All of the results of these tests show that the mechanical behaviour at large strains seems to be closely linked to the visco-elastic behaviour of the constitutive material studied by DMA. A specific set-up was design to impose low or high temperatures during a dynamic loading. Loadings in the dynamic regime at low temperatures were not enough for the constitutive materials to reach the glassy plateau and therefore they were still in their $\alpha$-transition. Experimental results from dynamic tests at high temperatures were very close at low strains and similar to quasi-static tests at ambiant temperatures. However, above a 0.1 strain, stresses were higher for higher strain-rates. This observation could indicate that specific mechanisms due to dynamic effects are happening in the cellular material.

To go further, an in-depth study at wisely chosen couples of strain-rates and temperatures need to be conducted. At the same time, a constitutive model taking into account the rheological behaviour of the constitutive materials will be developped. Together, experiemental and numerical simulation could be able to say wether dynamic effects such as inertia at the microscopic scale or gas compression are happening or if the strain-rate dependency of polymeric cellular materials comes only from the constitutive materials.

\section{Acknowledgements}

This work was performed in the framework of the LIAMA project (supported by Lieges HPK, Safran Power Unit (PU) and Region Nouvelle Aquitaine). The authors are very grateful to Agnes de Montbrun and Olivier Pauly from Lieges HPK and Romain Quinton from Safran PU for their scientific and technical contributions to this study. 


\section{References}

[1] L.J. Gibson, K.E. Easterling, M.F. Ashby, Proceedings of the Royal Society A: Mathematical, Physical and Engineering Sciences 377, 99 (1981)

[2] F.A.O. Fernandes, R.J.S. Pascoal, R.J. de Sousa, Materials Design 58, 499 (2014)

[3] S. Sanchez-Saez, S.K. García-Castillo, E. Barbero, J. Cirne, Materials Design 65, 743 (2015)

[4] P.T. Santos, S. Pinto, P.A. Marques, A.B. Pereira, R.J. Alves de Sousa, Composite Structures 178, 277 (2017)

[5] M. Ptak, P. Kaczyński, J. Wilhelm, J.M. Margarido, P.A. Marques, S.C. Pinto, R.J. de Sousa, F.A. Fernandes, Materials 12 (2019)

[6] M. Ptak, P. Kaczynski, F.A. Fernandes, R.J. de Sousa, International Journal of Impact Engineering 106, 238 (2017)

[7] P. Kaczynski, M. Ptak, J. Wilhelm, F.A. Fernandes, R.J. de Sousa, International Journal of Impact Engineering 126, 109 (2019)

[8] L. Le Barbenchon, J.B. Kopp, J. Girardot, P. Viot, Mechanics of Materials (2020)

[9] L. Le Barbenchon, J. Girardot, J.B. Kopp, P. Viot, Materialia 5 (2019)

[10] J.F. Mano, Journal of Materials Science 37, 257 (2002)

[11] N.G. Karsli, A. Aytac, Composites Part B: Engineering 51, 270 (2013)

[12] A. Lagorce-Tachon, T. Karbowiak, D. Champion, R.D. Gougeon, J.P. Bellat, Materials and Design 82, 148 (2015)

[13] P. Viot, International Journal of Impact Engineering 36, 975 (2009)

[14] P. Viot, International Journal of Impact Engineering 36, 975 (2009)

[15] R. Bouix, P. Viot, J.L. Lataillade, International Journal of Impact Engineering 36, 329 (2009)

[16] C. Menager, N. Guigo, X. Wu, L. Vincent, N. Sbirrazzuoli, Composites Part A: Applied Science and Manufacturing 124, 105473 (2019)

[17] T. Thomas, H. Mahfuz, L.A. Carlsson, K. Kanny, S. Jeelani, Composite Structures 58, 505 (2002)

[18] B. Song, W.Y. Lu, C.J. Syn, W. Chen, Journal of Materials Science 44, 351 (2009)

[19] H. Pereira, Wood Science and Technology 22, 211 (1988)

[20] S.P. Silva, M.A. Sabino, E.M. Fernandes, V.M. Correlo, L.F. Boesel, R.L. Reis, International Materials Reviews 50, 345 (2005)

[21] C.P. Gameiro, J. Cirne, G. Gary, Journal of Materials Science 42, 4316 (2007)

[22] S.J. Green, F.L. Schierloh, R.D. Perkins, S.G. Babcock, Experimental Mechanics 9, 103 (1969) 